\title{
The Impacts of Conditional Cash Transfers in Four Presidential Elections (2002-2014)*
}

\author{
Cesar Zucco Jr. \\ Fundação Getúlio Vargas - Rio de Janeiro, Brazil
}

This research note examines the electoral impacts of Conditional Cash Transfer programs in the 2014 presidential election, and compares these to results previously obtained for the preceding three elections (ZUCCO, 2013). It analyzes both individual-level survey data and municipal-level electoral data and applies different matching techniques to attempt to ensure that only similar individuals and municipalities are compared to each other. The note shows that although the strictly defined "electoral effect" of Bolsa Família at the municipality level has remained quite similar to what was found in the past elections, there seems to have been a sharp increase in the aggregate effects, observed at the municipality level. I conjecture that the increased polarization among non-beneficiaries is the possible "cause" of the changes observed in the last election and suggest that examining the indirect electoral effect of Bolsa Família over non-beneficiaries is a promising avenue for future research.

Keywords: Brazil; Bolsa Família; electoral effects; municipalities; 2014 elections.

\footnotetext{
Cince after President Lula's reelection in 2006, the Bolsa Família

Program (hereafter BFP) has captured the imagination of scholars,
} journalists, pundits, and the public alike, as a key determinant of presidential

(*) http://dx.doi.org/10.1590/1981-38212014000200006

The replication dataset can be found in http://bpsr.org.br/files/arquivos/Banco_Dados_ Zucco.html.

The author thanks BPSR anonymous reviewers for insightful comments on earlier versions as well as Daniel Bramatti for helping obtain survey data for 2014. The previous version of this research was presented at the II International Conference on Comparative Presidential Studies and Presidentialism held at UFGM. 
elections. Much scholarly ink has been spilled not only in assessing the impacts of the program but also in interpreting the meaning of such effects. Those studying the Brazilian case have contributed directly to a wider literature on electoral effects of conditional cash transfer (CCT) programs, which has resulted on studies about the CCT experiences in countries including (but not limited to) Mexico (DE LA 0, 2013; DIAZ-CAYEROS and MAGALONI, 2009), Uruguay (MANACORDA et al., 2011), Honduras (LINOS, 2013), and Turkey (AYTAC, 2014)ํ․

While in some countries scholars were able to explore the existence of randomized pilots (e.g., Mexico and Honduras) or sharp and well-defined discontinuities in the implementation of the program (e.g., Uruguay), the way in which the program was set up and rapidly expanded in Brazil relegate us to more traditional observational approaches, which are inherently limited in assessing causal effects ${ }^{2}$. This is especially the case in Brazil, where BFP coverage is fairly well targeted and correlates with many variables that presumably affect voting behaviors.

Despite the usage of varied methodological approaches to overcome the above mentioned difficulties, most studies on the Brazilian case have found positive effects of BFP on vote for the incumbent and thus corroborate findings of other studies on CCT programs around the world (HUNTER AND POWER, 2007; LÍCIO et al., 2009; NICOLAU AND PEIXOTO, 2007; ZUCCO, 2008, 2013; and for a divergent position see SHIKIDA et al., 2009).

In 2014, however, Brazil experienced its fourth election under the presence of CCTs, which allows us to consider not only whether there is existence of electoral effects of these programs but also how these effects might be evolving.

In this paper, I apply the approach presented by Zucco (2013) and extend it to include the 2014 elections. The approach's first defining feature is that it estimates the electoral effects of BFP using both individual-level survey data and municipal-level electoral data. The second important feature is the use of different matching variants to ensure that only similar individuals and municipalities are compared to each other.

\footnotetext{
1 There is a sprawling literature on the socio-economic impacts of CCTs, which this paper does not address. For a very comprehensive survey of these impacts, see Fiszbein et al. (2009).

2 On this topic, see for instance, Dunning (2012).
} 
The paper proceeds as follows: the next two sections provide the essential details of the approach, which is thoroughly described in Zucco (2013), and refer to the analysis of individual-level survey data and aggregate-level electoral results, respectively. The subsequent section presents the estimates of effects and is followed by a discussion of particularities of the 2014 results. I then briefly discuss the notion of a "Bolsa Família" effect and the final section concludes.

\section{Individual survey data}

Surveys, in general, have the appealing feature of providing data at the individual level. On the other hand, surveys are simply "stated preferences", which means that we have to rely on respondents correctly depicting their beneficiary status, voting intentions, and most other defining features. Moreover, the specific surveys we use are national in scope. They are rarely representative of sub-units and rarely ever indicate the municipality in which the respondents lives. This limits the comparisons between voters of different areas of the country.

Surveys that have asked respondents about whether they were beneficiaries of the BFP and who they intended to vote for (or recalled voting for) have been fielded since at least 2005, but I was unable to locate any such survey for the 2002 election. In this paper, I examine one Vox Populi survey taken a few days before the 2006 election, two surveys from 2010-one carried out by Ibope a few days before the election as well as the third wave of the Brazilian Electoral Panel Survey that was conducted a few weeks after the election, and three surveys from 2014 carried out in May and just after the first round of the election, including one Ibope survey conducted just before the election as well as the first and fifth waves for the Brazilian Electoral Panel Survey. The details of surveys used in this paper are presented in the appendix.

For each survey, I applied essentially the same analysis method, which consisted of pre-processing the complete micro-data set to ensure balance between BFP beneficiaries and non-beneficiaries on observed covariates (HO et al., 2007). This was done by matching beneficiaries to non-beneficiaries on gender, age, income, education, region, race (when available), and municipality's human 
development index (HDI-M) of respondents ${ }^{3}$. Matching was done using the genetic matching algorithm, developed by Diamond and Sekhon (2005). This eliminated non-beneficiaries for which there were no comparable beneficiaries (and vice versa). This ensured that at least on these observable variables, the set of beneficiaries and non-beneficiaries was very similar.

The graphical analysis of balance suggests that post-matching samples are indeed very well balanced on observables. Due to space constraints, I present below simply the Hansen and Bowers (2008) overall balance statistics ${ }^{4}$.

Table 01. Hansen and Bowers (2008) balance statistics for all surveys

\begin{tabular}{cccc}
\hline & Chi2 & df & p-value \\
Vox 2006 & 1.781 & 16 & 1.00 \\
Ibope 2010 & 2.836 & 18 & 1.00 \\
BEPS 2010 & 13.029 & 17 & 0.73 \\
Ibope 2014 & 1.199 & 22 & 1.00 \\
BEPS 2014 pre electoral & 11.184 & 18 & 0.89 \\
BEPS 2014 post electoral & 6.117 & 17 & 0.99 \\
\hline
\end{tabular}

Source: ZUCCO_DATABASE.

Note: The table reports results of a test in which the null hypothesis is that the (postmatching) treatment and control groups are the same. The high p-values indicate that the two groups are, by these criteria, effectively indistinguishable.

After balancing, the effects of the BFP are estimated by simple differences in proportions, which can be interpreted as the difference in probabilities of voting for the incumbent in the two groups. Here I departed from Zucco (2013), who estimated more specified logit analysis, because our wider array for surveys implied that different variables were available for different years. Given that the balance was very good, I opted to simplify the analysis and present exactly the same statistic for each survey.

The results are presented in Figure 01 below, along with the aggregate data estimates, to which I now describe.

\section{Aggregate electoral data}

Electoral results are revealed preferences and therefore superior to survey data in terms of credibility. However, electoral results are (thankfully) not

\footnotetext{
${ }^{3}$ Not all surveys included information on the municipality where respondents lived.

${ }^{4}$ Graphical analysis of balance and tables of differences in standardized means for a large set of variables for the six surveys can be obtained from the author.
} 
observed at the individual level, which limit our capacity to make inferences about individual behavior.

In Brazil, electoral results can be observed at lower aggregation levels, but BFP coverage and other social indicators are available only at the municipality level. Moreover, as mentioned in the opening sections, the BFP coverage is quite accurate in aggregate terms, implying that similar municipalities have similar coverage. This renders the analysis difficult.

Our approach is to treat the BFP coverage as a "continuous treatment" and to employ a generalized version of propensity score matching, proposed by Imai and Van Dyk (2004). The first step in the method consists of computing the predicted treatment level in each municipality. In our case, this is greatly facilitated by the existence of a "target" coverage for the BFP, to which I added HDI-M (as well as a HDI-M squared and cubed), distance to the capital city, share of the Pentecostal evangelical population, share of the non-white population, municipality's GDP per capita in the year of the election as well as a few political variables (Lula's vote share in the 1998 presidential election, and dummies indicating whether the mayor and governor were from the Work's Party (PT) or Brazilian Social-Democracy Party (PSDB), the two main parties contesting presidential elections) 5 .

The BFP target was by far the strongest predictor of coverage, and the political variables seem to add little to the mix. The same variables were used for all years, except for GDP level in the previous year, which is not yet available for 20146 .

The essence of the method is to treat deviations from the predicted treatment level as essentially random variation and to use this variation to identify the BFP effects on electoral results ${ }^{7}$. This is done by stratifying the data into

\footnotetext{
${ }^{5}$ HDI-M was obtained from IPEADATA, a data repository maintained by IPEA, which is a government-owned think tank for applied economic research; municipal characteristics were obtained from the Brazilian Geographical and Statistical Institute (IBGE); and electoral data from the electoral authority (TSE).

6 These data are released by IBGE with up to a two-year lag, so I resorted to the last available figures (2012).

7 To this end, it is very important that the treatment is predicted well. In all years, the R2 of the first-stage regression was very high $(2002=0.81,2006=0.88,2010=0.91$, and $2010=0.95$ ), and the analysis of residuals suggests that it is predicted equally well across the coverage range.
} 
subsamples of municipalities that have similar predicted BFP coverage (defined as the share of families in the municipality that receive benefits). For each group, I estimate a linear regression of coverage on incumbent vote share, controlling for the predicted coverage and including only indicators for states. The effects reported in Figure 1 are the average of the effects across all strata.

\section{Results}

Figure 01 reports the two sets of estimates. It is important to first note that the estimates in the two estimations are quite different. The individual-level data provide us with the effects of being a BFP beneficiary on the probability that an individual votes for the incumbent candidate, which is estimated by comparing beneficiaries to similar non-beneficiaries. The aggregate data allow for the estimation of the effect of increasing BFP coverage in a municipality on the vote share obtained by the incumbent party presidential candidate, which is estimated by comparing municipalities that are very similar but that have slightly varying coverage levels.

To compare the two quantities, I project the individual-level estimates to the aggregate level by computing the implied effect of increasing the BFP coverage by one percentage point. In these projections, I assume that the effects of individual-level estimates on beneficiaries are as estimated by the survey data and that non-beneficiaries are unaffected by BFP8. It turns out that under this second assumption-which I discuss at length later in the text-an increase in one percentage point of coverage is exactly the estimated effect at the individual level, which greatly facilitates the comparison? ${ }^{9}$

\footnotetext{
8 This is akin to assuming no "macro-effects" (or making the SUTVA assumption).

9 This is the case because beneficiaries and non-beneficiaries are complementary quantities. Say the estimated individual-level effect of being a BFP beneficiary is d, with the probability of a non-beneficiary voting for the incumbent is $p$ and the probability of a beneficiary is $p+d$. An increase in one percentage point of coverage implies a decrease in one percentage point in non-coverage; thus, in effect the increase in coverage implies gaining $p+d$ and losing $p$ for a net gain of vote share of $d$, which is the individual-level effect.
} 
Figure 01. Estimated effects of Bolsa Família on incumbent candidate vote share (2002-2014)

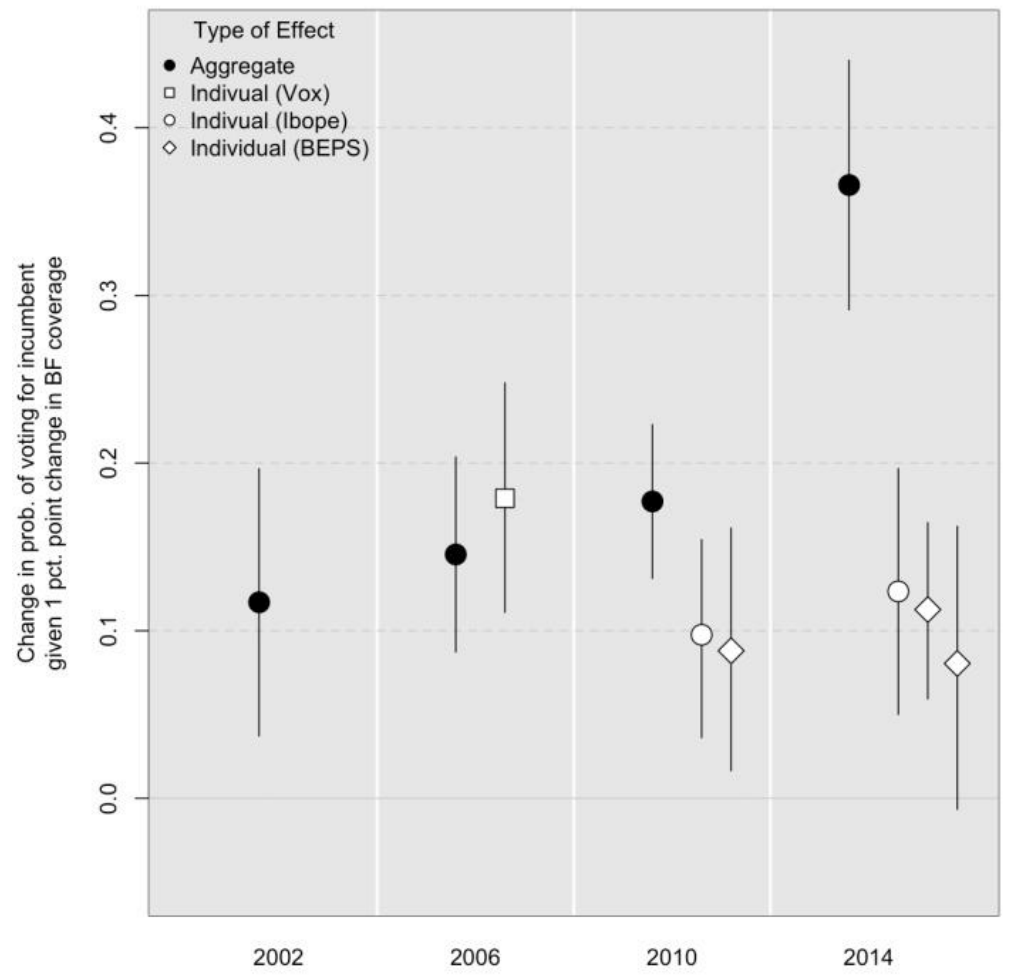

Source: ZUCCO_DATABASE.

The individual-level estimates are not available for 2002. They corresponded to a 0.18 increase in the probability of voting for Lula in 2006 and then reduced to about 0.1 in the last two elections with some variations across survey instruments. The first point to note, in fact, is that this variability across surveys highlights that surveys are noisy and therefore not always obviously superior to revealed preferences ${ }^{10}$.

In contrast, the aggregate estimates suggest some stability of the effects of the first three elections. The important feature of the data, and the one that I dwell on in the rest of the paper, is that the aggregate estimates and individual-level estimates were quite compatible in 2006 and 2010, but the former have shot up in 2014. Before turning to this point, note that the estimates show that BFP has a

10 The results presented here for 2002, 2006, and 2010 are almost identical to those presented in the right panel of Figure 01 of Zucco (2013) under the heading "GPS Matching" and "Survey (Implied)". 
clear electoral effect in all elections, including the one in 2002 when the incumbent was not from PT and when nobody was really paying attention to the federal government's social programs.

Moreover, this effect was never large enough to swing an election, at least until 2014. "Back-of-the-envelope" calculations based on individual-level estimates suggest that something close to 3.2 and 2.0 million votes might have been swayed in 2006 and 2010, respectively ${ }^{11}$. Aggregate effects point to 1.1, 2.6, and 3.6 million in 2002 through 2010. Individual estimates for 2014 indicate 2.8 million votes were swayed while the aggregate figures suggest a whopping 8.1 million votes. The estimates for 2014 differ from past years both because of the discrepancy between the two approaches and because, for the first time, one estimate was almost as large as the difference between the two main candidates (in the first round, and larger than the difference in the second round).

\section{Understanding the 2014 discrepancy}

While it is possible that at least part of the discrepancy between the individual-and aggregate-level estimates for 2014 are driven by some data limitations, something must have happened in the last presidential election that did not happen before if the method is to be believed. Even with "outdated" values for GDP growth by municipality, for instance, it is possible to predict Bolsa Família coverage quite well, which is the essential step in the approach. In addition, the method was identical to what was employed in all years, with the sole exception that not all surveys used contain the same individual-level variables to match beneficiaries. With this disclaimer in mind, the rest of the paper assumes that something substantive is driving the discrepancy.

Higher aggregate than individual-level effects imply that some process is magnifying the electoral effects of the BFP. Given the matching method employed, it is also known that irrespective of the process, the aggregates have to be highly correlated with the coverage of the BFP itself.

11 These estimates assume an average of two voters per beneficiary family, and equal turnout between beneficiary and non-beneficiary voters. I then project the estimated individual effects onto the share of voters that are beneficiaries. Needless to say, this is a very rough estimate. 
The hypothesis I put forth is that in 2014, non-beneficiaries voted for Dilma at much higher rates in places with high BFP coverage than in places with low BFP coverage, and that this difference was larger than that in previous years. In other words, non-beneficiaries must have been much more polarized across municipalities with different coverage levels than before.

This hypothesis is not directly testable with the data at hand because it makes predictions about quantities that cannot be observed. National surveys, such as the ones used here, allow us to infer the behavior of beneficiaries and nonbeneficiaries but are not fine grained enough to allow us to infer how this behavior varies with characteristics of the municipalities in which they live, which would be required to test the hypothesis. An alternative empirical approach would be to employ ecological inference models to estimate the behavior of beneficiaries and non-beneficiaries in each municipality (see, for instance, IMAI et al., 2008; KING, 1997). While this is something I leave for future work, ecological inference techniques are quite controversial and would not provide enough "evidence" to conclusively solve the riddle when singly employed.

As a first approach, in this section, I employ simulations to combine the information that is certain with information that might be true to gain insight into a few quantities that cannot be observed directly.

In these simulations, I conceptually divided the population of each municipality into three groups: Bolsa Família Program beneficiaries (indicated by "BF" in Figure 02), non-beneficiaries that are similar to beneficiaries (henceforth "poor non-BF"), and a third group to which I refer to as "non-poor".

The share of the population covered in each municipality is known. I assume the share that corresponds to the "poor non-BF" to be the difference between the coverage and the coverage target if the coverage is lower than the target, and zero otherwise. The remainder of the population of each municipality is considered to be "non-poor".

Given these quantities, Dilma's vote share can be computed assuming that each group has a certain probability of voting for Dilma in each municipality. The simulations consisted of searching for these probabilities for each group that would produce the observed vote patterns (i.e., Dilma's average vote share and cumulative vote share by BFP coverage levels), holding fixed the difference in 
probability of voting for Dilma between the poor non-BF and the beneficiaries that was estimated earlier and reported in Figure 01.

That said, is it possible to arrive at Dilma's observed distribution of vote share by BFP coverage level and its cumulative vote total by BFP vote-share level by assuming that beneficiaries voted at higher rates than similar beneficiaries, as estimated above in 2010 and 2014 ?

The two panels in Figure 02 show simulated probabilities for the three groups of BFP coverage levels that yield voting patterns almost identical to what was actually observed in each of the last two elections. I make no claim here that these represent unique "solutions" to the problem posed, as the simulations were done manually (as opposed to analytically). This exercise should therefore be treated simply as a first approach to the problem.

Figure 02. Simulated probabilities of voting for Dilma given Bolsa Família coverage (2010-2014)

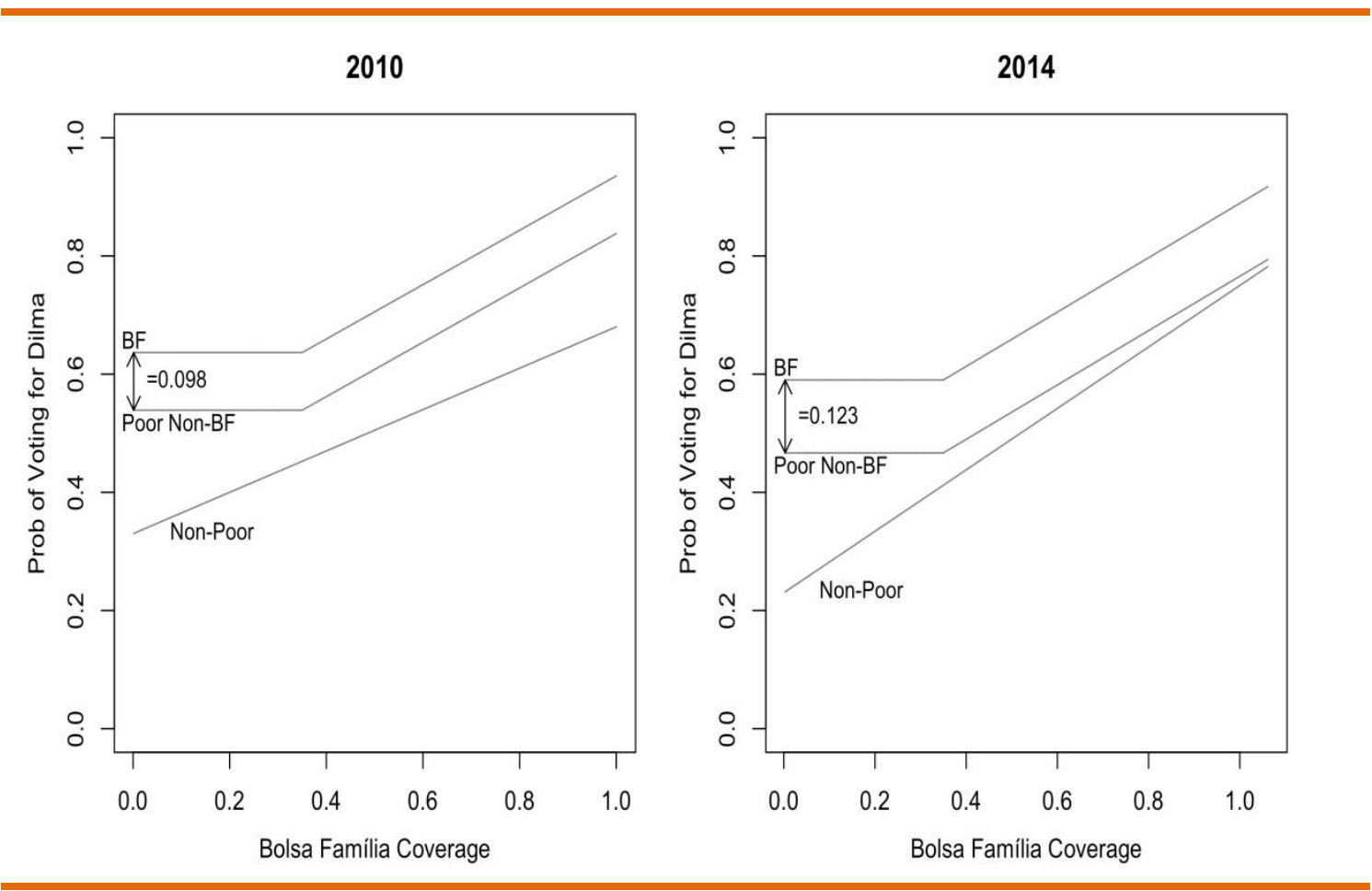

Source: ZUCCO_DATABASE.

The simulated patterns are similar in both years, with the main differences being the degree to which non-beneficiaries voted for Dilma across BFP coverage levels. The slope of the probability of non-poor (non-beneficiaries) voting for 
Dilma given BFP coverage is substantially larger in 2014, with vote share at low coverage being lower and at high coverage being higher than those in the previous year. In contrast, the simulated slope for the "poor" (both beneficiaries and nonbeneficiaries) is essentially the same in both years.

This increase in the slope for the non-poor is particularly consequential because the left side of the graph includes large rich municipalities such as São Paulo, which contain a significant share of the electorate and relatively few beneficiaries. Hence, changes in behavior of non-beneficiaries between the two elections had important electoral consequences.

The "real world" substantive meaning of this change in slope is that in 2014, the BFP elicited a far larger response by non-beneficiaries. Part of the reason for this was perhaps that there was a relatively large consensus around BFP, which is reflected in the very high "approval" rates for the program found in 2006 and 2010 surveys (AMES et al., 2010; IBOPE, 2006). A relatively "flat" behavior of the non-poor relative to BFP coverage in the municipality would not have magnified the individual-level effects of the program too much.

In contrast, in 2014, the BFP became much more controversial. Even though all main candidates pledged to support and even strengthen the program, no voters that disliked the program voted for the incumbent, and the program being cited as an example of what is wrong with the country. If support for the program slipped among the better off, the end result could have been the much steeper relationship between the vote of the non-poor for the incumbent and the BFP coverage.

This steep curve "explains" the magnification of the BFP electoral effects because it implies not only those beneficiaries voted for incumbents at a rate larger than that of non-beneficiaries but also that non-beneficiaries voted for the incumbents at rates that are more directly proportional to coverage. Therefore, in places with large coverage, the incumbent collected a lot of votes from those covered as well as a lot of votes from those non-covered, with the opposite being true in places with little coverage.

Note that the overall drop in support for Dilma between 2010 and 2014 might have been primarily driven by adverse economic conditions. What this analysis shows is simply that this drop followed the pattern of distribution of the 
BFP. This suggests that even if the drop was motivated by non-BFP-related conditions, the program helped mediate how this shock got translated into votes. One possibility is that the worsening economic conditions led to the increased polarization over the BFP, possibly because places with high coverage were shielded from some of the effects of the downturn. However, this interpretation is just a conjecture at this point and should be treated as a hypothesis that awaits a more direct verification.

\section{Are these indirect effects attributable to BFP?}

Figure 02 also raises an important conceptual question. In a straightforward manner, we can define a direct BFP effect at the individual level through the comparison of otherwise similar beneficiaries and non-beneficiaries indicated by the distance between the parallel lines representing each group. However, the simulations indicate that assuming this effect is true and given the known quantities in the population (i.e., CCT coverage, share of poor and non-poor in each municipality), we can only arrive at the observed electoral results if we allow the voting probabilities of both the covered and uncovered poor and the non-poor to vary across coverage levels.

Can this variation across coverage levels be called an "indirect" effect of BFP? Given the method used, the indirect effect could be caused by anything that is closely related to the BFP coverage. Therefore, additional social programs targeted at similar population, government expenditures that flow to the same municipalities covered by BF, and the like are possible candidates. Thus, future work will have to disentangle the effects of each of these. However, it is at least plausible (though it has not yet been verified) that this is directly related with BF itself, both in terms of positive spillover effects in places of high coverage and negative "backlash" effects in places of low coverage. This is a topic that future work will have to dwell on with more attention than that has been devoted to it in the past.

\section{Conclusion}

This paper extended existing approaches to estimate the electoral impact of the BFP to the 2014 presidential election. In the analysis, it combined the 
individual-level survey data with electoral data aggregated at the municipality level and showed that although the strictly defined "electoral effect" of Bolsa Família at the municipality level has remained quite similar to what was found in the past elections, there seems to have been a sharp increase in the aggregate effects, observed at the municipality level.

The results for 2014 are still tentative because not all data to fully replicate the analysis conducted in the preceding years are yet available. Still, the paper conjectured that the increased polarization among non-beneficiaries is the possible "cause" of the changes observed in the last election. While this conjecture is not tested directly, simulations show that it is at least compatible with the results that we observed.

If true, this conjecture raises the vexing issue of whether we can (and should) define an indirect Bolsa Família electoral effect that affects nonbeneficiaries. Both the strict test of the conjecture and the conceptual issue it raises should be dealt with in future work.

Revised by Cabo Verde Submitted in December 2014

Accepted in February 2015

\section{References}

AMES, B.; MACHADO, F.; RENNÓ, Lucio; SAMUELS, D.; SMITH, A. and ZUCCO Jr., C. (2010), Brazilian Electoral Panel Survey. IADB Working Paper, December.

AYTAC, S. E. (2014), Distributive politics in a multiparty system: The conditional cash transfer program in turkey. Comparative Political Studies. Vol. 47, № 09, pp. 1211-1237.

DE LA O, A. L. (2013), Do conditional cash transfers affect electoral behavior? Evidence from a randomized experiment in Mexico. American Journal of Political Science. Vol. 57, № 01.

DIAMOND, A. and SEKHON, J. S. (2005), Genetic matching for estimating causal effects: a general multivariate matching method for achieving balance in observational studies. Technical report. Department of Political Science. UC, Berkeley.

DIAZ-CAYEROS, A. and MAGALONI, B. (2009), Aiding Latin America's poor. Journal of Democracy. Vol. 20, № 04, pp. 36-49, October.

DUNNING, T. (2012), Natural experiments in the social sciences: a design-based 
approach. Cambridge University Press.

FISZBEIN, A.; SCHADY, N.; FERREIRA, F.; GROSH, M.; KELLEHER, N.; OLINTO, P. and SKOUFIA, E. (2009), Conditional Cash Transfers: Reducing Present and Future Poverty. World Bank Policy Research Report. World Bank, Washington, D.C.

HANSEN, B. B. and BOWERS, J. (2008), Covariate balance in simple, stratified and clustered comparative studies. Statistical Science. Vol. 23, № 02, pp. 219-236.

HO, D. E. , IMAI, K.; KING, G. and STUART, E. (2007), Matching as nonparametric preprocessing for reducing model dependence in parametric causal inference. Political Analysis. Vol. 15, № 03, pp. 199-236, Summer.

HUNTER, W. and POWER, T. (2007), Rewarding Lula: Executive power, social policy and the brazilian elections of 2006. Latin American Politics and Society. Vol. 49, № 01, pp. 01-30, March.

IBOPE (2006), Intenção de voto para presidente 2006 - Ibope/BR2006.SET02358. Interviewed 2,002 people on September 6. In: Banco de Dados do Centro de Estudos de Opinião Pública. Ed. CESOP-UNICAMP. http://www.cesop.unicamp.br/.

IMAI, K. and DYK, D. van (2004), Causal inference with general treatment regimes: generalizing the propensity score. Journal of the American Statistical Association. Vol. 99, № 467, pp. 854-866, Sep..

IMAI, K.; LU, Y. and STRAUSS, A. (2008), Bayesian and likelihood inference for $2 \mathrm{x}$ 2 ecological tables: an incomplete data approach. Political Analysis. Vol. 16, № 01, pp. 41-69, Winter.

KING, G. (1997), A solution to the ecological inference problem: reconstructing individual behavior from aggregate data. Princeton University Press, Princeton.

LICIO, E.; CASTRO, H. and RENNÓ, L. (2009), Bolsa família e voto nas eleições presidenciais de 2006: em busca do elo perdido. Opinião Pública. Vol. 15, № 01, pp. 29-58.

LINOS, E. (2013), Do conditional cash transfer programs shift votes? Evidence from the Honduran. Electoral studies. Vol. 32, № 04, pp. 864-874.

MANACORDA, M.; MIGUEL, E. and VIGORITO, A. (2011), Government transfers and political support. American Economic Journal: Applied Economics. Vol. 03, № 03, pp. 01-28, July.

NICOLAU, Jairo and PEIXOTO, Vitor (2006), As bases municipais da votação de Lula em 2006. Fórum Nacional Position Paper \#2. http://www.forumnacional.org.br/forum/pforum62a.asp 
SHIKIDA, C. D.; MONASTERIO, L. M.; ARAÚJO Jr, A. F.; CARRARO, A. and DAMÉ, O. (2009), It is the economy, companheiro!: an empirical analysis of Lula's reelection based on municipal data. Economics Bulletin. Vol. 29, № 02, pp. 976999.

VOX POPULI (2006), Intenção de voto para presidente 2006. interviewed 2005 people on Oct. 16th and 17th. In: CESOP-UNICAMP, editor, Banco de Dados do Centro de Estudos de Opinião Pública.

ZUCCO Jr., C. (2008), The presidents 'new' constituency: Lula and the pragmatic vote in Brazil's 2006 presidential election. Journal of Latin American Studies. Vol. 40, № 01, pp. 29-49, February.

ZUCCO Jr., C. (2013), When payouts pay off: conditional cash-transfers, clientelism, and voting behavior. American Journal of Political Science. Vol. 47, № 03.

\section{Appendix}

Table 02. List of surveys used in the analysis

\begin{tabular}{lcc}
\hline & $\mathrm{N}$ & Date \\
Vox 2006 & 2006 & Oct 2006 \\
Ibope 2010 & 2002 & Sep 2010 \\
BEPS 2010 & 1221 & Dec 2010 \\
Ibope 2014 & 3005 & Oct 2014 \\
BEPS 2014 pre electoral* & 3120 & May 2014 \\
BEPS 2014 post electoral & 1207 & Oct 2014 \\
\hline
\end{tabular}

Source: CESOP, IADB, IBOPE.

Note: *The dataset for the 2014 BEPS will be made available in 2015. 